\title{
Biometric Factors Associated with the Visual Performance of a High Addition Multifocal Intraocular Lens
}

Joaquín Fernández, Manuel Rodríguez-Vallejo, Javier Martínez, Ana Tauste \& David P Piñero

To cite this article: Joaquín Fernández, Manuel Rodríguez-Vallejo, Javier Martínez, Ana Tauste \& David P Piñero (2018): Biometric Factors Associated with the Visual Performance of a High Addition Multifocal Intraocular Lens, Current Eye Research, DOI: 10.1080/02713683.2018.1478981

To link to this article: https://doi.org/10.1080/02713683.2018.1478981

Accepted author version posted online: 18 May 2018.

Submit your article to this journal $\pi$

山 Article views: 3

View related articles

View Crossmark data $₫$ 


\title{
Biometric factors associated with the visual performance of a high addition multifocal intraocular lens
}

\author{
Joaquín Fernández, MD, PhD; ${ }^{1,2}$ Manuel Rodríguez-Vallejo, OD, PhD; ${ }^{1^{*}}$ Javier \\ Martínez, OD; ${ }^{1}$ Ana Tauste, OD, PhD; ${ }^{1}$ David P Piñero, OD, PhD $^{3,4}$ \\ ${ }^{1}$ Department of Ophthalmology (Qvision), Vithas Virgen del Mar Hospital, 04120, Almería, Spain \\ ${ }^{2}$ Department of Ophthalmology, Torrecárdenas Hospital Complex, 04009, Almería, Spain \\ ${ }^{3}$ Department of Optics, Pharmacology and Anatomy, University of Alicante, Alicante, Spain \\ ${ }^{4}$ Department of Ophthalmology (OFTALMAR), Vithas Medimar International Hospital, Alicante, Spain \\ *Corresponding author: manuelrodriguezid@qvision.es (Tel+34686500808)
}

Number of Figures: 3 Number of Tables: 2

Biometric factors and visual performance with a MIOL

\section{Submitted: February 2, 2018}

\section{Abstract}

Purpose/Aim: To evaluate the impact of ocular parameters on the visual performance achieved with the multifocal intraocular lens (IOL) Bi-Flex M 677MY.

Materials and Methods: 26 subjects were included in the current study. Several physiological variables were retrieved from the 3-month follow-up visit, including pupil diameter and distance from pupil center to the vertex normal of the anterior cornea $(\mu)$. These variables were also obtained in the preoperative visit. Binocular and monocular visual acuity defocus curves were measured at 1 and 3 months after surgery, respectively. The area under the monocular defocus curve was computed along the total curve (TAUC, +1.00 to $-4.00 \mathrm{D}$ ) and for the ranges of far (FAUC, +0.50 to $-0.50 \mathrm{D}$ ), intermediate (IAUC, -1.00 to $-1.50 \mathrm{D}$ ) 
and near vision (NAUC, -2.00 to $-4.00 \mathrm{D}$ ). Correlations between these areas and the postoperative physiological variables were assessed.

Results: The mean $\mu$ was reduced from $0.21 \mathrm{~mm}$ to $0.10 \mathrm{~mm}$ after surgery, as well as pupil diameters, either photopic $(-7.4 \%)$ and mesopic $(-8.1 \%)(\mathrm{p}<0.05)$. The mean AUCs were 2.08 \pm 0.74 for TAUC, $0.57 \pm 0.17$ for FAUC, $0.16 \pm 0.09$ for IAUC and $0.81 \pm 0.29$ for NAUC. Significant correlations were found between NAUC and Km $(r=-0.39, p=0.05)$ as well as between IAUC and temporal decentration of the lens from vertex normal $(\rho=-0.41, p=$ $0.04)$.

Conclusions: The performance at near with the IOL evaluated improved in eyes with less corneal power. On the other hand, a slight temporal IOL decentration from vertex normal also improved intermediate visual acuity. The binocular defocus curve was similar to other trifocal IOLs.

Key Words: multifocal intraocular lens, visual acuity defocus curves, corneal power, lens centration, effective addition.

\section{Main text introduction}

Standards for reporting results achieved with multifocal intraocular lens (MIOLs) have been defined in order to compare results among different MIOLs. ${ }^{1}$ These standards include the methodology of plotting and summarizing results about safety, efficacy, and predictability. However, despite these standards are quite useful for comparing results among IOLs, they fail in terms of including information about how eye parameters can affect the performance achieved with a particular IOL. It has been previously reported that variations in eye characteristics can affect the performance achieved with a specific MIOL. Some of these parameters include angle kappa and MIOL (related to the presence of dysphotopsia), ${ }^{2,3}$ 
corneal spherical aberration, ${ }^{4,5}$ regular corneal astigmatism, ${ }^{6,7}$ corneal irregular astigmatism, ${ }^{8,9}$ and effective lens addition. ${ }^{10-12}$ The literature is full of studies reporting results with several MIOLs according to the standards, ${ }^{13-24}$ but it is still not clear the influence of biometric factors on the performance of each particular IOL according to the characteristics of the patient. The main aim of this study was to evaluate the performance of a high addition MIOL by means of computing the area under the visual acuity defocus curve $e^{25}$ and correlate it with several biometric parameters.

\section{Materials and methods}

\section{Subjects}

This study was approved by the Ethics Committee of Research, Almería Center, Torrecardenas Hospital Complex, and performed in adherence to the tenets of the Declaration of Helsinki. Written informed consent was obtained from each patient before the surgical procedure. Data of 26 eyes from 26 subjects implanted with a high addition MIOL at Qvision (Department of Ophthalmology, Virgen del Mar Hospital, Almería, Spain) were retrospectively retrieved from our historical database. Only one eye randomly selected per subject was included in the monocular data analysis. Eyes that presented corneal epithelial erosions during surgery were excluded from the monocular and binocular analysis of the Visual Acuity Defocus Curve (VADC), whereas eyes that presented small anterior capsule tears were included in the analysis.

\section{Surgery procedure and intraocular lens description}

All the eyes retrospectively retrieved were operated on by the same surgeon (JF) by means of femtosecond laser-assisted cataract surgery (Victus, Bausch \& Lomb Inc, Dornach, Germany) through a temporal clear corneal incision (CCI) of $2.5 \mathrm{~mm}$. The IOL included in 
the analysis was the diffractive trifocal IOL Bi-Flex M 677MY (Medicontur Medical Engineering Ltd. Inc., Zsámbék, Hungary), which has a $6 \mathrm{~mm}$ biconvex aspheric optic and a central diffractive Elevated Phase Shift (EPS technology) for the constructive generation of the intermediate foci. The labelled addition power at the IOL plane is $+3.50 \mathrm{D}$ for the near vision and $+1.75 \mathrm{D}$ for intermediate vision. The platform consist of a double-loop haptic without angulation. The haptic locations during the implantation were oriented in the temporal nasal direction.

\section{Measured variables}

Biometrical parameters retrieved from the preoperative visit included chord mu $(\mu)^{26}$ and pupil diameter measured with Pentacam HR (Oculus, Wetzlar, Germany), as well as photopic (PP) and mesopic pupil (MP) diameters measured with the Keratograph 5M system (Oculus, Wetzlar, Germany). The binocular VADC measured with the Multifocal Lens Analyzer ${ }^{27}$ was retrieved from the 1-month follow-up visit whereas the monocular VADC was retrieved from the 3-month visit. Several eye parameters were measured in the 3-month visit and included in the data analysis: mean corneal power (Km) and axial length (AXL) measured with the IOL Master 500 system (Carl Zeiss Meditec Inc., Dublin, CA, USA), and the corneal parameters included in the "Cataract Pre-Op" modulus of Pentacam HR that included total regular astigmatism (RA), irregular astigmatism for a 4-mm corneal diameter (IA), and spherical aberration for a 6-mm corneal diameter (SA). Likewise, the PP and MP measured with the Keratograph 5M, the total spherical aberration recomputed for the MP size (SAM) with the "Zernike Analysis" modulus of Pentacam HR, as well as the actual lens position from anterior corneal surface to anterior MIOL surface (ALP), $\mu$ and pupil diameter measured with the Pentacam HR were also considered in the data analysis. The addition at the corneal plane was computed considering the dioptric power of the implanted MIOL, approximating ALP to 
ELP ${ }^{28}$ and the $\mathrm{Km}$ according to the Holladay's refractive vergence formula. ${ }^{12}$ Then, the effective addition (EA) at the spectacle plane was computed considering a vertex distance of $12 \mathrm{~mm}$.

A slit lamp picture was taken in each case and an ordinal scale was used to evaluate subjectively the degree of MIOL centration. The geometric center of the IOL diffractive rings were compared to the position of the pupil center, considering a negative displacement for temporal or inferior directions and a positive displacement for superior or nasal directions. The centration was established horizontally and vertically $(\mathrm{H}, \mathrm{V})$, with the following ordinal scale: 0 , the first ring was centered on the pupil; 1 , the first ring was $25 \%$ decentered; 2 , the first ring was $50 \%$ decentered and the pupil center was coincident with the edge of the first ring; 3, the pupil center was coincident with the second ring; 4, the pupil center went beyond the second ring. We assumed that the diameter of the first ring was approximately $1.2 \mathrm{~mm}$ at the corneal plane, the level 1 would correspond to an approximated decentration of $0.3 \mathrm{~mm}$ and the level 2 to a decentration of $0.6 \mathrm{~mm}$. Thus, the MIOL centration with respect to the vertex normal was computed considering $\mathrm{d}_{\mathrm{x}}=\mathrm{H}^{*} 0.3-\mu_{\mathrm{x}}$ and $\mathrm{d}_{\mathrm{y}}=\mathrm{V}^{*} 0.3-\mu_{\mathrm{y}}$, where $\mathrm{d}$ is the distance from the vertex normal to the center of the ring, $\mathrm{H}$ and $\mathrm{V}$ were the subjectively ordinal scale results, $\mu$ is the distance from pupil center to the vertex normal measured with Pentacam HR, and $0.3 \mathrm{~mm}$ is a $25 \%$ of displacement assuming a diameter of the first ring of $1.2 \mathrm{~mm}$ at the corneal plane. Figure 1 describes the use of this scale of centration analysis in a case from the sample for a better understanding of the method: (A) The subjective centration can be qualified as $\mathrm{H}:-1$ and $\mathrm{V}:-1$ according to the slit-lamp picture; (B) pupil diameter measured with Pentacam HR was $2.54 \mathrm{~mm}, \mu_{\mathrm{x}}=0.07 \mathrm{~mm}$ and $\mu_{\mathrm{y}}=0.28 \mathrm{~mm}$; (C) considering that the first ring size was $1.2 \mathrm{~mm}$, the pupil diameter in the slit-lamp picture was calculated with the image ${ }^{29}$ software by matching the value of $2.54 \mathrm{~mm}$ obtained from Pentacam HR and overlapping slit-lamp and Pentacam HR pictures, obtaining a d value with imageJ of 0.74 
$\mathrm{mm}$. With our method based on subjective grading, we obtained a value of $0.69 \mathrm{~mm}$ using the equation 1 , with only a bias of $0.05 \mathrm{~mm}$ compared to the imageJ method.

$$
\begin{gathered}
d=\sqrt{\mathrm{d} x^{2}+\mathrm{d}_{y}{ }^{2}}=\sqrt{\left(\mathrm{H} * 0.3 \mathrm{~mm}-\mu_{x}\right)^{2}+\left(\mathrm{V} * 0.3 \mathrm{~mm}-\mu_{y}\right)^{2}} \\
d=\sqrt{(-1 * 0.3-0.07)^{2}+(-1 * 0.3-0.28)^{2}}=0.69 \mathrm{~mm}
\end{gathered}
$$

\section{Figure 1}

\section{Statistical analysis}

As the $\mu$ measured with Pentacam included right and left eyes randomly selected, a conversion of the center of coordinates was applied before the analysis in such a way positive values indicate a nasal location of the vertex normal to the pupil and negative values indicate temporal location of the vertex normal to the pupil with independence of the included eye, either right or left. Furthermore, the sign for vertical position of $\mu$ was inverted from that obtained directly from Pentacam in such a way that positive indicates vertex normal above pupil center and negative the opposite, either for right or left eyes. This conversion was applied with some functions detailed in the Refractive Analysis (1.0.0) toolbox for Matlab. ${ }^{30}$ A MATLAB function (The Mathworks Inc., Natick, MA, USA) was developed in order to compute the area under the curve (AUC) for the total measured range from +1.00 to $-4.00 \mathrm{D}$ (TAUC), for the far range (FAUC: +0.50 to $-0.50 \mathrm{D}$ ), the intermediate range (IAUC: -1.00 to $-1.50 \mathrm{D})$ and the near range (NAUC: -2.00 to $-4.00 \mathrm{D})$. For this purpose, the trapz function included in MATLAB was used for computing the AUC $\left(\log M A R * m^{-1}\right)$ above $0.3 \log$ MAR in the previous detailed ranges. ${ }^{25}$ This function performs numerical integration via the trapezoidal method. The method approximates the integration over an interval by breaking the area down into trapezoids with more easily computable areas. ${ }^{31}$ 
The normality of data distributions of the variables included in the study was tested with the Shapiro-Wilk test. Mean differences between preoperative and postoperative variables were assessed with the Student paired t-test. Furthermore, correlations were also evaluated with the Pearson or the Spearman's correlations coefficients depending if the correlated variables followed or not a normal distribution, respectively. The statistical analyses were performed using the IBM SPSS 20.0 software for Windows (SPSS, Chicago, IL). Mean \pm standard deviation is used in the results section for reporting central tendency and data dispersion.

\section{Results}

The sample included eyes from 5 men and 21 women with mean age of $67.6 \pm 7.9$ years, ranging from 48 to 83 years old. Two subjects presented epithelial corneal erosions in one eye during surgery, and therefore contralateral eye was selected. In these specific cases, the selection of one eye was not done randomly as only one eye was available, and these subjects were excluded from the binocular analysis. Two eyes presented small anterior capsule tears during the surgery, but these eyes were included either in the monocular and binocular analysis. No other adverse events occurred during surgery. Table 1 shows the descriptive statistics for the biometric parameters measured at 3-month follow-up visit.

\section{Table 1}

$\mu_{\times}$was significantly reduced after surgery, with a mean difference of $-0.08 \pm 0.18 \mathrm{~mm}$ $(\mathrm{t}=2.36, \mathrm{p}=0.03)$. The difference was similar, but not statistically significant for $\mu_{\mathrm{y}},-0.08 \pm$ $0.23 \mathrm{~mm}(\mathrm{t}=1.78, \mathrm{p}=0.09)$. Figure 2A shows a reduction of mean $\mu$ from $0.21 \mathrm{~mm} @ 32^{\circ}$ (SDx: $0.2 \mathrm{~mm}$, SDy: $0.26 \mathrm{~mm}$ ) preoperatively to $0.10 \mathrm{~mm} @ 18^{\circ}$ (SDx: $0.12 \mathrm{~mm}, \mathrm{SDy}: 0.15$ $\mathrm{mm}$ ) postoperatively. Pupil diameter was also reduced significantly after surgery, either for $\mathrm{PP}$ (mean: $-0.26 \pm 0.45 \mathrm{~mm},-9.09 \%, \mathrm{t}=2.93, \mathrm{p}=0.007), \mathrm{MP}(-0.47 \pm 0.75 \mathrm{~mm},-10.31 \%, \mathrm{t}=$ 
3.16, $\mathrm{p}=0.004$ ) or pupil measured with Pentacam HR (mean: $-0.26 \pm 0.49 \mathrm{~mm},-9.42 \%, \mathrm{t}=$ 2.66, $\mathrm{p}=0.014)$. The magnitude difference from preoperative and postoperative $\mu$ was correlated with the Pentacam HR difference in pupil diameter $(\rho=0.43, p=0.03)$.

In 9 eyes, the MIOL was not decentered horizontally $(\mathrm{H}=0), 14$ showed $\mathrm{H}=-1$ (25\% first ring temporal to pupil) and 3 showed $\mathrm{H}=1$ (25\% first ring nasal to pupil). With regard to vertical centration, it was $V=0$ for 12 eyes, $V=-1$ ( $25 \%$ first ring below pupil) for 10 eyes and $V=1$ (25\% first ring above pupil) for 4 eyes. Then, all the MIOLs resulted in a decentration from pupil center of equal or less than $25 \%$ the size of the first ring. Figure $2 \mathrm{~B}$ shows the mean IOL center from the vertex normal (mean: $0.25 \mathrm{~mm} @ 204^{\circ}$, SDx: $0.23 \mathrm{~mm}$, SDy: $0.24 \mathrm{~mm}$ ).

\section{Figure 2}

The mean AUCs were $2.08 \pm 0.74$ for TAUC, $0.57 \pm 0.17$ for FAUC, $0.16 \pm 0.09$ for IAUC and $0.81 \pm 0.29$ for NAUC. Figure $3 \mathrm{~A}$ shows a mean monocular visual acuity of $-0.03 \pm 0.10$ $\log$ MAR at far $(0 \mathrm{D}$, infinite $), 0.2 \pm 0.16 \log$ MAR at intermediate $(-1.5 \mathrm{D}, 67 \mathrm{~cm})$ and $0.05 \pm$ 0.09 at near $(-3.0 \mathrm{D}, 33 \mathrm{~cm})$. Mean binocular visual acuity obtained from the defocus curve was $-0.05 \pm 0.11 \log$ MAR at far, $0.15 \pm 0.15 \log$ MAR at intermediate and $0.01 \pm 0.11$ $\log$ MAR at near (Figure 3A).

\section{Figure 3}

Mean EA was $2.25 \pm 0.06 \mathrm{D}$, which differs from the mean value of $3.0 \mathrm{D}$ obtained from the point of best vision at the defocus curve (Figure 3A). We conducted an analysis of the location of the best vision peak at near for each eye. Three eyes had the peak at $-2.0 \mathrm{D}, 10$ at 2.5 D, 8 at $-3.0 \mathrm{D}, 4$ at $-3.5 \mathrm{D}$ and 1 at $-4 \mathrm{D}$. This means that even though the mean was located at -3.0 D, a high number of eyes achieved the best vision for a defocus level of $-2.5 \mathrm{D}$ $(40 \mathrm{~cm})$. Furthermore, the addition obtained from the defocus curve was significantly 
correlated with the EA $(\rho=0.38, p=0.05)$. Figure 3B shows the mean defocus curve for each subset of eyes that presented the peak of best near vision for different levels of defocus.

No significant correlations of defocus curve areas with any of the biometric parameters measured were found, except for the $\mathrm{Km}$ that was negatively correlated with NAUC $(\mathrm{r}=-$ $0.39, p=0.05)$ and $d_{x}$ that was negatively correlated with IAUC $(\rho=-0.41, p=0.04)($ Table 2).

\section{Table 2}

\section{Discussion}

In the present study, we analyzed the influence of several biometric factors on the area under the visual acuity defocus curve of a high addition multifocal lens. Some of these biometric factors such as $\mu$-chord or the pupil diameter were compared before and after surgery. Interestingly, the $\mu$-chord was significantly reduced after surgery (from 0.21 to $0.10 \mathrm{~mm}$, $\sim 50 \%$ ) which means that the distance between pupil center and vertex normal was reduced. Furthermore, the pupil diameter was reduced either for PP (-9.09\%), MP (-10.31\%) and Pentacam HR (-9.42\%). Our results corroborate the findings obtained by Kanellopoulos et al, ${ }^{32}$ showing a reduction of the $\mu$-chord from 0.12 to $0.05 \mathrm{~mm}(\sim 50 \%)$ and a photopic and mesopic pupil diameter reduction of $-9.8 \%$ and $-9.1 \%$, respectively, after cataract surgery. The correlation between pupil change of Pentacam and difference in $\mu$-chord after surgery suggest that the variation in $\mu$-chord is mainly due to the variation of pupil center position with pupil diameter change as it has been previously reported. ${ }^{32}$

The $\mu$-chord, which is correlated with kappa angle, ${ }^{26,33}$ has been hypothesized to be related with the visual performance achieved with MIOLs. ${ }^{34}$ However, to this date, there is only one clinical study that correlates the kappa angle with the visual performance. Prakash et $\mathrm{al}^{3}$ 
conducted a regression analysis in order to report that haloes depended on angle kappa and distance UCVA, whereas glare only depended on kappa. However, the statistical analysis of their study is highly questionable because they used a regression analysis in a sample that hardly accomplished the required assumptions for accepting the consistency of the model, according to the data distributions shown in the figures reported. Furthermore, they used the Orbscan system ${ }^{4}$ (Bausch \& Lomb, Rochester, New York, USA), which defines the Kappa angle as the angle difference between the axis of fixation and the optical axis perpendicular to the lens. ${ }^{5}$ This definition considerably differs from the difference between the first Purkinje image and the pupillary axis commonly measured by other corneal topographers. ${ }^{6}$ Karhanová et $\mathrm{al}^{35}$ reported that temporal decentration of a MIOL was related with a higher risk of postoperative photic phenomena, and later they conducted a theoretical study in which they concluded that shallow anterior chamber depth in connection with a higher angle kappa is an important risk factor for pronounced photic phenomena. ${ }^{2}$ Dysphotopsia was not part of our study, but we evaluated the influence of the $\mu$ in the visual performance, obtaining no significant correlations between $\mu$ postoperatively and AUCs. On the other hand, we found a significant negative correlation between IAUC and $d_{x}$, which means that eyes with temporal decentration of the lenses from the vertex normal $(\leq 0.55 \mathrm{~mm})$ tend to experience an increase in the performance at intermediate distance with the MIOL evaluated. Interestingly, the same tendency but not reaching statistically significant was found for the other ranges of vision, which means that this slight temporal decentration from vertex normal might also increase the visual performance at other distances. This increase of intermediate vision with decentration is not in agreement with optical bench measures with other trifocal IOLs, ${ }^{36}$ therefore it might be not explained by the decentration between optical structures. The location of the common optical axis in reference to the fovea and neural processing should be considered. Future studies should include a detailed analysis of dysphotopsia in order to 
confirm if this range of temporal decentration increases or not the risk of the symptoms as has been hypothesized. ${ }^{35}$ We aware that our methodology for evaluating IOL centration has some important limitations in order to precisely measure the centration. The centration was based on a subjective ordinal scale interpretation and the size of the first ring at the corneal plane was assumed to be $1.2 \mathrm{~mm}$. This size depends on real size of the first ring, corneal power and distance from lens to the cornea. ${ }^{37}$ Therefore, a variation between eyes is expected and an assumption is required.

Despite these approximations can lead to a systematic error, they would not affect to the conclusions obtained in the study because the systematic error is applied in all the eyes and therefore the correlations observed will be maintained. On the other hand, an important advantage of our methodology is that can be easily adapted by clinicians in order to implement it in their practice because not expensive devices and software are required. Subjective ordinal scales are very useful in clinical practice when advanced systems are not available, such as the Lens Opacities Classification System III versus densitometry or ocular scatter index. ${ }^{38}$ This is the first time that a subjective scale is proposed for measuring IOL centration with slit-lamp and the agreement with more precise technologies as $\mathrm{OCT}^{39}$ or the inter-experimenter reproducibility of the grading should be assessed in future studies.

We compared the binocular defocus curve of the MIOL from the current study versus that reported by other authors for the trifocal IOL FineVision, as it has the same labeled near addition $(+3.5$ D). Despite the follow-up can vary between studies, defocus curves are measured with best distance spectacle refraction and at this condition no significant differences have been reported between 1 and 12 month follow-up. ${ }^{18}$ Our binocular visual acuity defocus curve results were similar $(\sim 0.15 \log \mathrm{MAR})$ at intermediate vision and superior at far $(<0 \log \mathrm{MAR})$ and near $(<0.1 \log \mathrm{MAR})$ distances than those reported by Cochener et al ${ }^{13}$ and Marques et $\mathrm{al}^{19}$. On the other hand, Jonker et al. ${ }^{13}$ reported similar results at near and 
far distances, better at intermediate, but less depth of field at near vision. Bilbao-Calabuig et $\mathrm{al}^{20}$ and Ruiz-Mesa et $\mathrm{al}^{23}$ also reported better results at intermediate vision, but poorer at near and distance. Although there are differences between studies probably due to the testing methodology, the comparison suggests that the lens of the present study behaves as a trifocal IOL. It is also important to note that our study has a limitation in the intermediate vision assessment. We conducted a sample size estimation with the formula for the minimum sample size for confidence intervals $(95 \%, z=1.96)$ at all the defocus lenses. ${ }^{40}$ Sample was enough for the standard deviation of $0.15 \log$ MAR and a desired margin error of 0.05 $\log$ MAR for far and near vision and $0.1 \log$ MAR for intermediate vision

The EA was computed and compared with the dioptric difference between far and near peaks of highest visual acuity. The mean effective addition was $2.25 \mathrm{D}$ (near focal point equal to 44 $\mathrm{cm}$ ), considering that mean $\mathrm{Km}$ was $43.65 \mathrm{D}$ and mean ALP was $4.44 \mathrm{~mm}$. We can conclude that our results are close to those theoretical reported by McKee et al ${ }^{12}(39 \mathrm{~cm}, \mathrm{Km}=43.5$, $\mathrm{ELP}=4.25 \mathrm{~mm})$ or Savini et $\mathrm{al}^{10}(42 \mathrm{~cm}, \mathrm{Km}=43.81 \mathrm{D}, \mathrm{AXL}=23.65 \mathrm{~mm})$ for a trifocal intraocular lens of $3.5 \mathrm{D}$ at the IOL plane. However, for the mean VADC, the peak of best near vision was at $-3.0 \mathrm{D}(33 \mathrm{~cm})$ of defocus which means that EA underestimates the defocus curves. In reference to this, we obtained defocus curves with the best near vision at different levels of defocus, mainly at -2.5 D and -3.0 D. Interestingly, the visual acuity at far distance $(0 \mathrm{D})$ remained constant as can be seen in Figure 1B and was not decreased until the highest near peak was at $-3.5 \mathrm{D}$. These results show that the addition varies between eyes and the positive correlation of the peak of best near visual acuity at the defocus curve with the EA suggests that the parameters involved in the calculation of EA might be the reason of this variation in the near peak location. In fact, $\mathrm{Km}$ was negatively correlated with the NAUC, which means that eyes with higher power have lower NAUC. According to our findings, Km is the most important factor in order to predict clinically the visual performance of the patient 
at near, even more important that the real measure of the ALP. Further studies with other MIOLs and higher samples are required to confirm our findings since although the correlation is not significant, TAUC also showed a tendency of decreasing with the increment of $\mathrm{Km}$. Therefore, some confounding factors affecting TAUC might have some influence on the NAUC besides EA.

It is important to note that the approximation of ALP to ELP of a thin lens is a limitation that can lead to an error. Holladay et al. $^{41}$ reported a particular case for which the ELP was 0.6 mm larger than the ALP and this value can vary depending on corneal power, IOL power, IOL design, etc. However, we computed the possible error in our study associated to the assumption of an ELP $0.6 \mathrm{~mm}$ systematically shorter and resulted in an overestimation of the EA of less than 0.2 D. Therefore, differences between addition computed from defocus curves and EA would have been higher if a more precise consideration of the ELP had been computed.

Studies reporting defocus curves average results obtained from patients reaching different near additions. As can be seen in Figure 3, this can lead to an underestimation of the visual acuity at the near peak of vision, $0 \log \mathrm{MAR}$ in Figure 3B and $0.05 \log \mathrm{MAR}$ in Figure $3 \mathrm{~A}$, and an overestimation of the near depth of field when the performance of the lens is interpreted from the average. Considering this fact, the standard deviation represented in the defocus curve could offer interesting information about the dispersion of the data, especially at intermediate and near. Furthermore, it is important to note that we used a fixed range for computing areas under the curve instead of centering each area symmetrically around the near focus detected because our aim was to assess how biometric parameters affect to the ranges of vision (FAUC: Infinite to $2 \mathrm{~m}$ ), the intermediate range (IAUC: $1 \mathrm{~m}$ to $67 \mathrm{~cm}$ ) and the near range (NAUC: $50 \mathrm{~cm}$ to $25 \mathrm{~cm}$ ) measured with defocus lenses. However, computing areas symmetrically around the detected near focus might improve the correlation with EA. It 
is also important to note that in the calculation of IAUC, the defocus lenses of $-0.5 \mathrm{D}$ and -2 D were not considered because this would include a wider range of distance from $2 \mathrm{~m}$ to 50 $\mathrm{cm}$. Only considering $-1.00 \mathrm{D}$ and $-1.5 \mathrm{D}$ for the calculation, a more reliable representation of the definition of intermediate vision is obtained, from $1 \mathrm{~m}$ to $67 \mathrm{~cm}$.

In conclusion, we evaluated the performance of a multifocal lens in terms of the AUC obtaining that NAUC was correlated with corneal power and IAUC with IOL centration. Eyes with less corneal power obtained higher NAUC and therefore better visual acuities at near. On the other hand, we found that intermediate vision in terms of IAUC increases with a temporal decentration versus the vertex normal of less than $0.55 \mathrm{~mm}(\sim 25 \%$ of the size of the central ring from pupil center). Despite we found significant correlations between EA and the peak of best vision at near, defocus curves overestimated the EA, and therefore reading distance should be included in studies that evaluate the variation of addition with biometric variables. Finally, the intraocular lens performance in terms of binocular visual acuity defocus curve was similar to that reported for lenses commercially classified as trifocal.

\section{Acknowledgments}

No Acknowledgments

\section{Declaration of interest statement}

MR-V has designed and programmed the Multifocal Lens Analyzer test used in the current study which is distributed by the Apple Store as well as the Refractive Analysis Toolbox for Matlab. The other authors report no conflicts of interest and have no proprietary interest in any of the materials mentioned in this article. 


\section{References}

1. Reinstein DZ, Archer TJ, Srinivasan S, Mamalis N, Kohnen T, Dupps WJ, Randleman JB. Standard for reporting refractive outcomes of intraocular lens-based refractive surgery. J Cataract Refract Surg. 2017;43(4):435-9.

2. Karhanová M, Pluháček F, Mlčák P, Vláčil O, Šín M, Marešová K. The importance of angle kappa evaluation for implantation of diffractive multifocal intra-ocular lenses using pseudophakic eye model. Acta Ophthalmol. 2015;93(2):e123-8.

3. Prakash G, Prakash DR, Agarwal A, Kumar DA, Jacob S. Predictive factor and kappa angle analysis for visual satisfactions in patients with multifocal IOL implantation. Eye. 2011;25(9):1187-93.

4. Liu J-P, Zhang F, Zhao J-Y, Ma L-W, Zhang J-S. Visual function and higher order aberration after implantation of aspheric and spherical multifocal intraocular lenses: a meta-analysis. Int J Ophthalmol. 2013;6(5):690-5.

5. de Vries NE, Webers CA, VerbakelF, de Brabander J, Berendschot TT, Cheng YY, Doors M, Nuijts RM. Visual outcome and patient satisfaction after multifocal intraocular lens implantation: aspheric versus spherical design. J Cataract Refract Surg. 2010;36(11):1897-904.

6. Hayashi K, Manabe SI, Yoshida M, Hayashi H. Effect of astigmatism on visual acuity in eyes with a diffractive multifocal intraocular lens. J Cataract Refract Surg. 2010;36(8):1323-9.

7. Hayashi K, Hayashi H, Nakao F, Hayashi F. Influence of astigmatism on multifocal and monofocal intraocular lenses. Am J Ophthalmol. 2000;130(4):477-82.

8. Maeda N. Assessment of corneal optical quality for premium IOLs with Pentacam. Highlights Ophthalmol. 2011;39(4):2-5.

9. De Vries NE, Webers CAB, Touwslager WRH, Bauer NJC, De Brabander J, Berendschot TT, Nuijts RMMA. Dissatisfaction after implantation of multifocal intraocular lenses. J Cataract Refract Surg. 2011;37(5):859-65.

10. Savini G, Hoffer KJ, Lombardo M, Serrao S, Schiano-Lomoriello D, Ducoli P. Influence of the effective lens position, as predicted by axial length and keratometry, 
on the near add power of multifocal intraocular lenses. J Cataract Refract Surg. 2016;42(1):44-9.

11. Eom Y, Song JS, Kim HM. Spectacle plane add power of multifocal intraocular lenses according to effective lens position. Can J Ophthalmol. 2017;52(1):54-60.

12. McKee HD, Jhanji V. Theoretical effect of lens position and corneal curvature on the near focal point of multifocal intraocular lenses. J Refract Surg. 2016;32(1):64-6.

13. Cochener B. Prospective clinical comparison of patient outcomes following implantation of trifocal or bifocal intraocular lenses. J Refract Surg. 2016;32(3):14651.

14. Jonker SM, Bauer NJ, Makhotkina NY, Berendschot TTJ, van den Biggelaar FJM, Nuijts RM. Comparison of a trifocal intraocular lens with a +3.0 D bifocal IOL: results of a prospective randomized clinical trial. J Cataract Refract Surg. 2015;41(8):163140.

15. Kohnen T, Titke C, Böhm M. Trifocal intraocular lens implantation to treat visual demands in various distances following lens removal. Am J Ophthalmol. 2016;161:7177.e1.

16. Kretz FTA, Breyer D, Diakonis VF, Klabe K, Henke F, Auffarth GU, Kaymak H. Clinical outcomes after binocular implantation of a new trifocal diffractive intraocular lens. J Ophthalmol. 2015;(962891).

17. Mojzis P, Peña-García P, Liehneova I, Ziak P, Alió JL. Outcomes of a new diffractive trifocal intraocular lens. J Cataract Refract Surg. 2014;40:60-9.

18. Mojzis P, Majerova K, Hrckova L, Piñero DP. Implantation of a diffractive trifocal intraocular lens: One-year follow-up. J Cataract Refract Surg. 2015;41(8):1623-30.

19. Marques EF, Ferreira TB. Comparison of visual outcomes of 2 diffractive trifocal intraocular lenses. J Cataract Refract Surg. 2015;41(2):354-63.

20. Bilbao-Calabuig R, González-López F, Amparo F, Alvarez G, Patel SR, Llovet-Osuna F. Comparison between mix-and-match implantation of bifocal intraocular lenses and bilateral implantation of trifocal intraocular lenses. J Refract Surg. 2016;32(10):65963. 
21. García-Pérez JL, Gros-Otero J, Sánchez-Ramos C, Blázquez V, Contreras I. Short term visual outcomes of a new trifocal intraocular lens. BMC Ophthalmol. 2017;17(1):72.

22. Plaza-Puche AB, Alió JL, MacRae S, Zheleznyak L, Sala E, Yoon G. Correlating optical bench performance with clinical defocus curves in varifocal and trifocal intraocular lenses. J Refract Surg. 2015;31(5):300-7.

23. Ruiz-Mesa R, Abengózar-Vela A, Aramburu A, Ruiz-Santos M. Comparison of visual outcomes after bilateral implantation of extended range of vision and trifocal intraocular lenses. Eur J Ophthalmol. 2017;27(4):460-5.

24. Torun Acar B, Duman E, Simsek S. Clinical outcomes of a new diffractive trifocal intraocular lens with Enhanced Depth of Focus (EDOF). BMC Ophthalmol. 2016;16(1):208.

25. Buckhurst PJ, Wolffsohn JS, Naroo SA, Davies LN, Bhogal GK, Kipioti A, Shah S. Multifocal intraocular lens differentiation using defocus curves. Investig Opthalmology Vis Sci. 2012;53(7):3920.

26. Chang DH, Waring GO. The subject-fixated coaxially sighted corneal light reflex: A clinical marker for centration of refractive treatments and devices. Am J Ophthalmol. 2014;158(5):863-874.e2.

27. Rodríguez-Vallejo M, Tauste A, Albarrán C, Basterra I, Piñero D, Fernández J. Validation of a new clinical system for the fast measure of defocus curves with iPad. Paper presented at the XXXV Congress of the ESCRS, Lisbon, 7-11 October 2017. In 2017.

28. Plat J, Hoa D, Mura F, Busetto T, Schneider C, Payerols A, Villain M, Daien V. Clinical and biometric determinants of actual lens position after cataract surgery. J Cataract Refract Surg. 2017;43(2):195-200.

29. Rueden CT, Schindelin J, Hiner MC, DeZonia BE, Walter AE, Arena ET, Eliceiri KW. ImageJ2: ImageJ for the next generation of scientific image data. BMC Bioinformatics. 2017;18(1):1-26.

30. Rodríguez-Vallejo M. Refractive Analysis v.1.0.0. A Matlab toolbox for the analysis of refractive results in anterior segment surgery. 2017 [accessed 2018 Jan 25]. http://test-eye.com/index.php/en/refractive-analysis 
31. Matlab Documentation. (trapz function) Trapezoidal numerical integration. 2017. https://es.mathworks.com/help/matlab/ref/trapz.html\#bua4lsr

32. Kanellopoulos AJ, Asimellis G, Georgiadou S. Digital pupillometry and centroid shift changes after cataract surgery. J Cataract Refract Surg. 2015;41(2):408-14.

33. Buehren T. The subject-fixated coaxially sighted corneal light reflex: A clinical marker for centration of refractive treatments and devices. Am J Ophthalmol. 2015;159(3):611-2.

34. Moshirfar M, Hoggan RN, Muthappan V. Angle Kappa and its importance in refractive surgery. Oman J Ophthalmol. 2013;6(3):151-8.

35. Karhanová M, Marešová K, Pluháček F, Mlčák P, Vláčil O, Sín M. [The importance of angle kappa for centration of multifocal intraocular lenses]. Cesk Slov Oftalmol. 2013;69(2):64-8.

36. Ortiz C, Esteve-Taboada JJ, Belda-Salmerón L, Monsálvez-Romín D, DomínguezVicent A. Effect of decentration on the optical quality of two intraocular lenses. Optom Vis Sci. 2016;93(12):1552-9.

37. López-Gil N, Castejón-Mochón JF, Fernández-Sánchez V. Limitations of the ocular wavefront correction with contact lenses. Vision Res. 2009;49(14):1729-37.

38. Crnej A, Hirnschall N, Petsoglou C, Findl O. Methods for assessing forward and backward light scatter in patients with cataract. J Cataract Refract Surg. $2017 ; 43(8): 1072-6$

39. Kimura S, Morizane Y, Shiode Y, Hirano M, Doi S, Toshima S, Fujiwara A, Shiraga F. Assessment of tilt and decentration of crystalline lens and intraocular lens relative to the corneal topographic axis using anterior segment optical coherence tomography. PLoS One. 2017;12(9):1-12.

40. Sullivan LM. Essentials of biostatistics in public health. London: Jones \& Bartlett Publishers; 2008. 156 p.

41. Holladay JT, Maverick KJ. Relationship of the actual thick intraocular lens optic to the thin lens equivalent. Am J Ophthalmol. 1998;126(3):339-47. 


\section{Figure captions}

Figure 1. Description of the subjective grading for the evaluation of the multifocal intraocular lens. A) IOL was decentered $\sim 25 \%$ temporal and down which corresponds to a grading (H: 1, V: -1); B) Corneal topography obtained from Pentacam HR which shows the $\mu$-chord from vertex normal to pupil (changed sign) and pupil diameter; C) Overlapping and centration measured with ImageJ software considering a first ring size of $1.2 \mathrm{~mm}$ which results in a bias of $0.05 \mathrm{~mm}$ in comparison to the calculation from the ordinal scale.

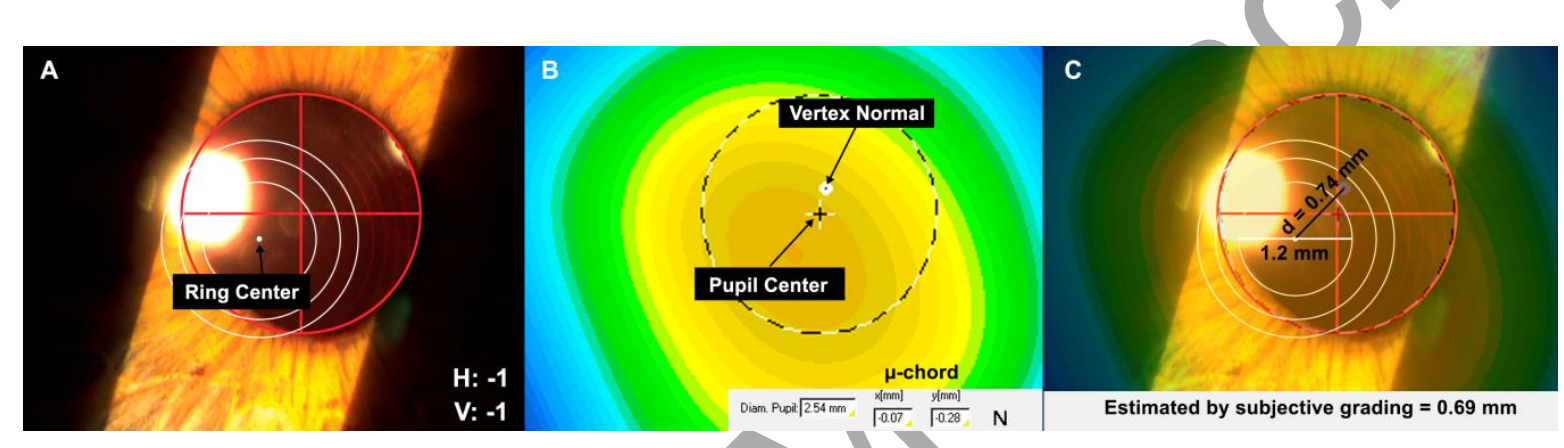


Figure 2. A) Location of the vertex normal from to the pupil center for preoperative and postoperative measures. Black triangles describe the mean and the ellipse around the triangles the standard deviation. B) Location of the intraocular lens (IOL) center to the vertex normal. Black circle describes the mean and the ellipse around the circle the standard deviation. Each ring on the plot describes a $0.2 \mathrm{~mm}$ step. Locations are nasal for $0^{\circ}$, superior for $90^{\circ}$, temporal for $180^{\circ}$ and inferior for $270^{\circ}$.
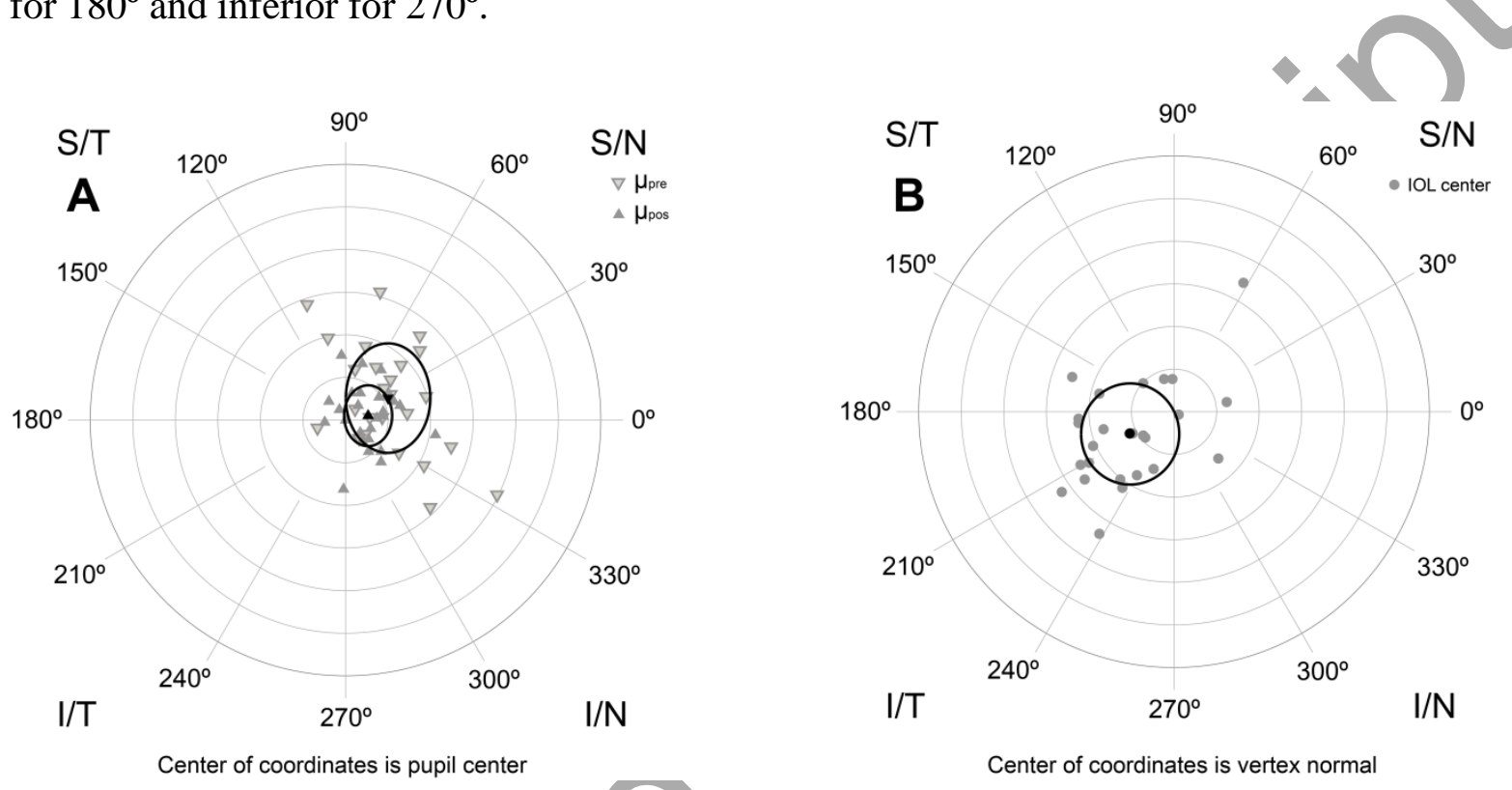
Figure 3. (A) Mean and standard deviation of monocular and binocular visual acuity defocus curves. (B) Mean and standard deviation of monocular subset visual acuity defocus curves presenting different locations of the peak of best near visual acuity.
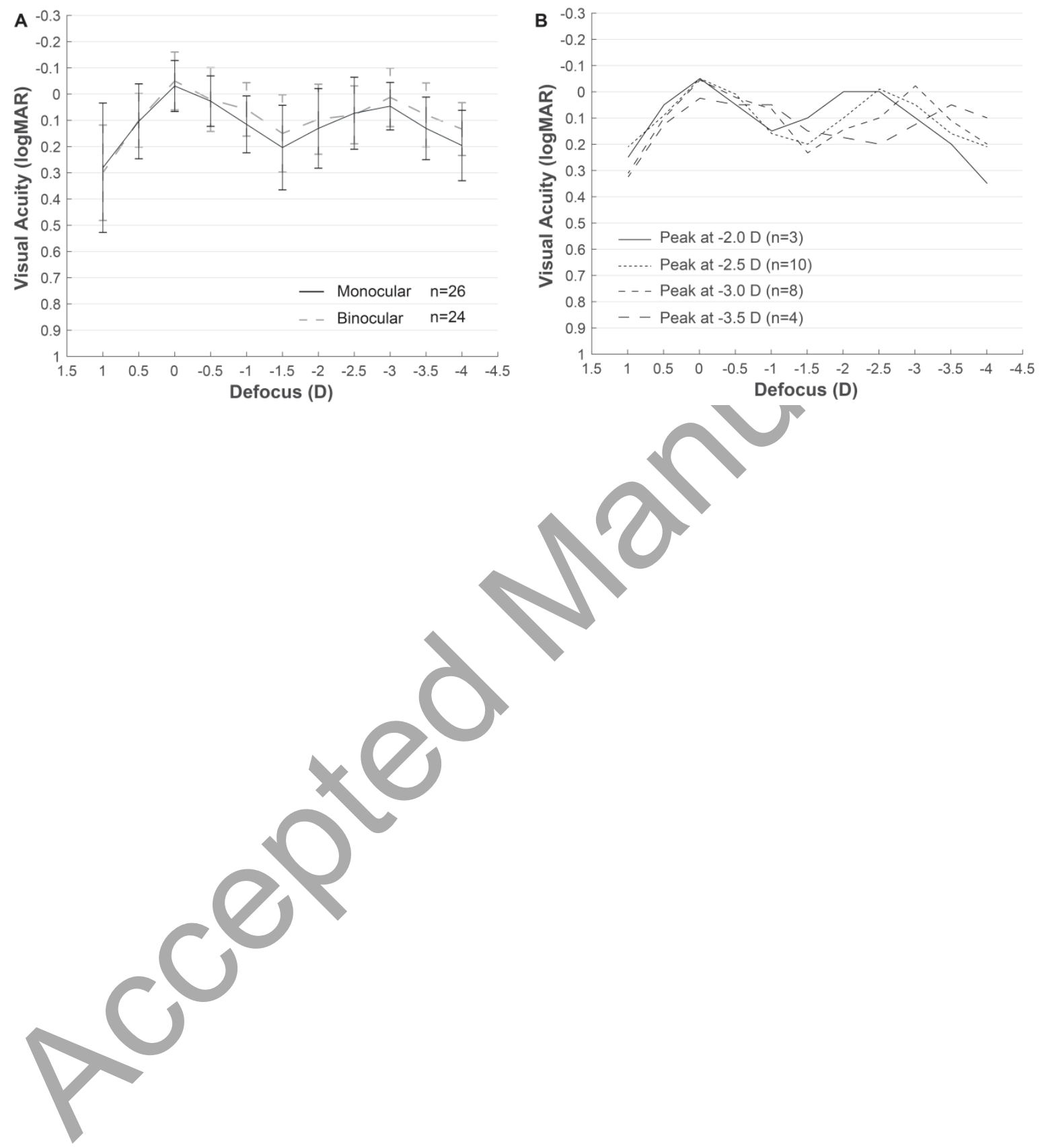
Table 1. Postoperative variables measured at 3-month follow-up visit.

\begin{tabular}{rc} 
Variable & mean \pm SD; median $(\mathrm{IQR})$ \\
\hline \hline Mean corneal power $(\mathrm{D})$ & $43.65 \pm 1.26 ; 43.63(1.53)$ \\
Axial length $(\mathrm{mm})$ & $23.37 \pm 1.13 ; 23.45(1.44)$ \\
Actual lens position $(\mathrm{mm})$ & $4.44 \pm 0.38 ; 4.42(0.42)$ \\
Intraocular lens power $(\mathrm{D})$ & $21.76 \pm 3.11 ; 21.75(3.63)$ \\
Effective addition $(\mathrm{D})$ & $2.25 \pm 0.06 ; 2.24(0.08)$ \\
Regular astigmatism $(\mathrm{D})$ & $0.63 \pm 0.34 ;-0.6(0.5)$ \\
Irregular astigmatism $(\mu \mathrm{m})$ & $0.17 \pm 0.06 ; 0.17(0.08)$ \\
Spherical aberration $(\mu \mathrm{m})$ & $0.31 \pm 0.10 ; 0.31(0.11)$ \\
Horizontal chord mu $(\mathrm{mm})$ & $0.10 \pm 0.12 ; 0.10(0.15)$ \\
Vertical chord mu $(\mathrm{mm})$ & $0.03 \pm 0.15 ; 0.04(0.19)$ \\
Horizontal IOL center to vertex normal $(\mathrm{mm})$ & $-0.22 \pm 0.23 ;-0.24(0.33)$ \\
Vertical IOL center to vertex normal $(\mathrm{mm})$ & $-0.10 \pm 0.24 ; 0.11(0.34)$ \\
Photopic pupil diameter $(\mathrm{mm})$ & $2.60 \pm 0.49 ; 2.55(0.70)$ \\
Mesopic pupil diameter $(\mathrm{mm})$ & $3.99 \pm 0.68 ; 3.90(0.90)$ \\
Spherical aberration for mesopic pupil $(\mu \mathrm{m})$ & $0.07 \pm 0.06 ; 0.06(0.09)$ \\
\hline \hline
\end{tabular}


Table 2. Visual acuity defocus curve versus biometric parameters

\begin{tabular}{rcccc} 
& \multicolumn{4}{c}{$\begin{array}{c}\text { Area under the curve }(\text { logMAR*mm } \\
\text { Correlation coefficient }(\mathrm{p} \text {-value })\end{array}$} \\
\cline { 2 - 5 } Variable & Total & Far & Intermediate & Near \\
\cline { 2 - 5 } Age & $-0.27(0.18)$ & $-0.33(0.1)$ & $0.13(0.51)^{\mathrm{a}}$ & $-0.31(0.12)$ \\
Km $(\mathrm{D})$ & $-0.28(0.17)$ & $-0.19(0.35)$ & $-0.12(0.57)^{\mathrm{a}}$ & $-0.39(0.05) *$ \\
AXL $(\mathrm{mm})$ & $0.25(0.22)$ & $0.31(0.12)$ & $0.02(0.91)^{\mathrm{a}}$ & $0.33(0.09)$ \\
ALP $(\mathrm{mm})$ & $0.21(0.31)$ & $0.29(0.16)$ & $-0.19(0.34)^{\mathrm{a}}$ & $0.31(0.12)$ \\
$\mathrm{EA}(\mathrm{D})$ & $-0.07(0.74)$ & $-0.13(0.51)$ & $0.25(0.22)^{\mathrm{a}}$ & $-0.16(0.45)$ \\
$\mathrm{RA}(\mathrm{D})$ & $0.12(0.57)$ & $0.32(0.11)$ & $-0.19(0.37)^{\mathrm{a}}$ & $0.15(0.48)$ \\
$\mathrm{IA}(\mu \mathrm{m})$ & $-0.15(0.48)$ & $-0.16(0.44)$ & $0.21(0.30)^{\mathrm{a}}$ & $-0.26(0.20)$ \\
$\mathrm{SA}(\mu \mathrm{m})$ & $-0.12(0.56)$ & $-0.08(0.71)$ & $-0.09(0.67)^{\mathrm{a}}$ & $-0.21(0.31)$ \\
$\mu(\mathrm{mm})$ & $0.02(0.91)$ & $-0.14(0.49)$ & $0.20(0.32)^{\mathrm{a}}$ & $0.02(0.92)$ \\
$\mu_{\mathrm{x}}(\mathrm{mm})$ & $0.24(0.24)$ & $0.12(0.55)$ & $0.28(0.16)^{\mathrm{a}}$ & $0.16(0.43)$ \\
$\mu_{\mathrm{y}}(\mathrm{mm})$ & $0.03(0.87)$ & $0.07(0.75)$ & $0.22(0.28)^{\mathrm{a}}$ & $0.02(0.92)$ \\
$\mathrm{d}(\mathrm{mm})$ & $0.10(0.64)$ & $0.11(0.59)$ & $0.17(0.42)^{\mathrm{a}}$ & $0.08(0.71)$ \\
$\mathrm{d}_{\mathrm{x}}(\mathrm{mm})$ & $-0.24(0.24)$ & $-0.20(0.34)$ & $-0.41(0.04)^{\mathrm{a}^{*}}$ & $-0.18(0.37)$ \\
$\mathrm{d}_{\mathrm{y}}(\mathrm{mm})$ & $-0.05(0.80)$ & $0.03(0.87)$ & $-0.1(0.64)^{\mathrm{a}}$ & $-0.09(0.67)$ \\
PP $(\mathrm{mm})$ & $0.03(0.85)$ & $0.19(0.35)$ & $-0.22(0.28)^{\mathrm{a}}$ & $0.06(0.77)$ \\
MP $(\mathrm{mm})$ & $0.11(0.59)$ & $0.24(0.24)$ & $-0.21(0.30)^{\mathrm{a}}$ & $0.10(0.64)$ \\
SAM $(\mu \mathrm{m})$ & $-0.24(0.25)$ & $-0.14(0.50)$ & $-0.32(0.11)^{\mathrm{a}}$ & $-0.25(0.23)$ \\
\hline \hline
\end{tabular}

Km: Mean corneal power; AXL: axial length; ALP: Actual lens position; EA: Effective addition; RA: Regular astigmatism; IA: Irregular astigmatism; SA: Spherical aberration at $6 \mathrm{~mm} ; \mu$ : distance from pupil center to vertex normal; $\mu_{\mathrm{x}}$ : $\mu$ in horizontal cartesian coordinates; $\mu_{\mathrm{y}}: \mu$ in vertical cartesian coordinates; $d$ : Intraocular lens centration from vertex normal; $\mathrm{d}_{\mathrm{x}}$ : $\mathrm{d}$ in horizontal cartesian coordinates; $\mathrm{d}_{\mathrm{y}}: \mathrm{d}$ in vertical cartesian coordinates; PP: Photopic pupil diameter; MP: Mesopic pupil diameter; SAM: Spherical aberration computed for mesopic pupil.

${ }^{a}$ Spearman rho instead of Pearson $r$.

$* \mathrm{p} \leq 0.05$ 